\title{
Analysis of IT Project schedule inaccuracy
}

\author{
Muhamad Ardika, Nurmala \\ \{muhamad.ardika94@gmail.com, nurmala.nn@yahoo.com\}
}

University of Indonesia, Bekasi, Indonesia

\begin{abstract}
Proper project planning is essential in determining the success of information and technology (IT) projects. Define the project scope, change request, can affect the planned project schedule. The purpose of this research is to identify the causes of inaccurate project schedules to be studied based on the project lifecycle. This research uses a case study on a IT consulting company in Indonesia. The analysis of this research is based on project lifecycle with Ishikawa Diagram, Pareto Diagram and Bayes Theorem. The results showed that the inaccuracy of the project schedule was caused by problems that occurred in various phases, but mainly due to problems that occurred in the analysis stage. The research results also indicate the mitigation priorities that need to be applied. The results of this study are expected to help players in the information technology consulting industry and other businesses to carry out project management more effectively.
\end{abstract}

Keywords: Ishikawa Diagram, Pareto Diagram, Bayesian Network, Project Management.

\section{Introduction}

Every IT consulting firm always handles more than one project at a time. Besides, their customers are not always in the same line of business. The number of customer business lines handled by technology and information consulting firms also influence the requirements collection phase. Also, the scope of the project and the type of project impact the project schedule. Inadequate collection of requirements by business analysts or unclear requirements described by customers can cause a mismatch in project schedules. Research relating to the causes and consequences of project delays is still limited. Previous research has focused on the differences between Intentional Attacks and Uncommon Technical Failures [1], quality and reliability in statistic[2], the application of continuous improvement [3]. 
In the world of IT consulting, frequently the schedule is designed not exactly what is being done. Careful planning that has been agreed by both parties. However, in the process of work there are things that can affect the schedule that is not right. Many factors influence this, such as features related to change requests, design errors, development errors and missed testing.

Based on the described case, what is the problem that causing inacuracy IT project shedule? In other words, in what phase the root cause in every phase in IT project management? This researh identifies the cause of the inacuracy IT project schedule. We analyze in every phase in IT project management that possibly became the root cause.

\section{Methodology}

\subsection{IT Project Management}

This section explained project management, and highlight their area in ICT (Information communication and technology) project. Project management is "the application of knowledge, skills, tools and techniques to project activities to meet project requirements.'[4]. Each project had many different stakeholders and often have different interests. Therefore project managers should develop good relationships with project stakeholders to understand and meet their needs and expectations.

There are two important steps that are common to all computer program development; Analysis and Coding. But he insisted that any plans to build a larger software system based solely on these two steps would fail [5].

For the purpose of addressing the IT project cycle holistically, the traditional System Development Lifecycle (SDLC) is best suited for defining the different phases of an ICT project, these phases are, planning, system, analysis, System design, Development, integration and testing, and Implementation and Maintenance.

\subsection{Quality Tools Project Management}


This section explains tools in IT project management. They are certainly different based on the techniques used. Project / team managers tend to use project management tools and Techniques to help focus on the end-user and business requirements of an organization. There are several quality tools project management whose benefit is to measure the quality of a project. And can be used as a repair monitoring tool. Tools which can be used include the Ishikawa diagram, Pareto diagram, Bayesian Network.

\section{Ishikawa Diagram}

Ishikawa diagrams help to systematically identify and organize the possible contributing factors of a particular problem. Figure 1 shows the generic structure of an Ishikawa diagrams, consisting of a problem and its possible subcauses or contributing fators sorted and related under different categories. The main cause of each problem is represented in each category. The classification scheme used for the application becomes a reference to the categories used in the Ishikawa diagram. In general, the causal relationship between cause and problem (effect) is represented by arrows on the Ishikawa diagram. The main advantages of the Ishikawa diagram include: (1) During the brainstorming session the Ishikawa diagram can be easily adapted, (2) The data collection process can be more conical based on encouragement and guidance from the Ishikawa diagram by showing a lack of knowledge, (3) Group participation can be stimulated by the Ishikawa diagram structure, (4) during the brainstorming session, the group can stay focused on the problem content based on the Ishikawa diagram structure.

Ishikawa Diagram used by Myers et al. to identify possible contributing factors to project quality that impact the project schedule, and to use four different categories to sort and correlate contributing factors [6]. 


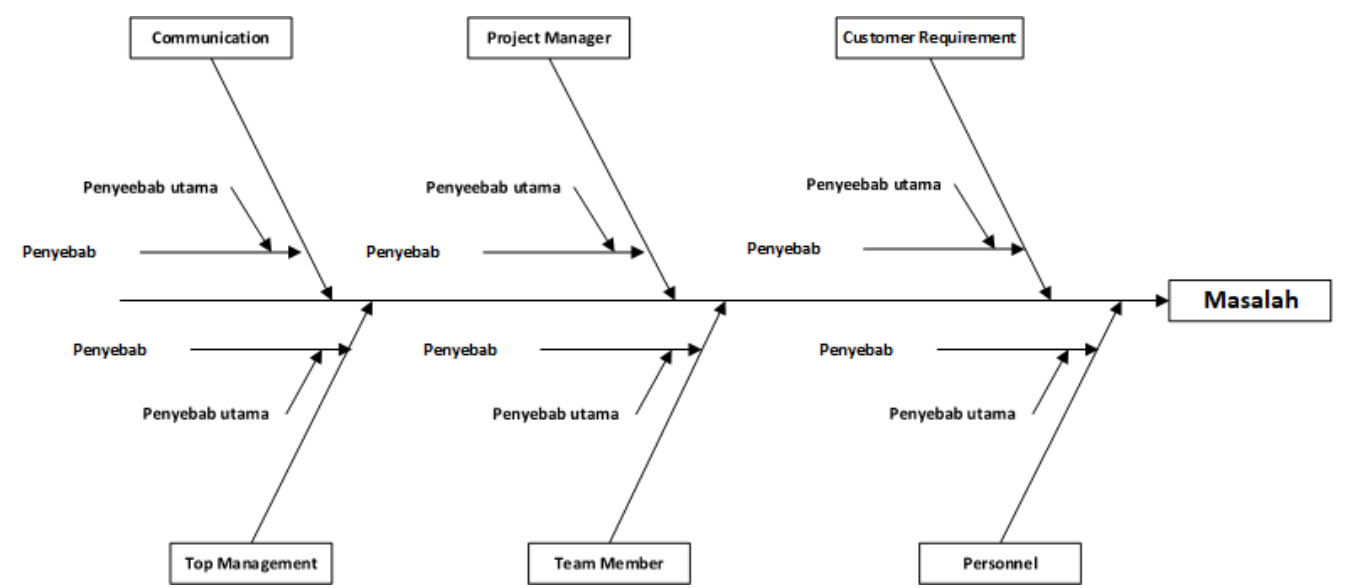

Fig. 1. Ishikawa Diagram Example

\section{Pareto Diagram}

Diagram pareto helps to identify the spread of the cause inacuracy IT project schedule. This diagram can be used to find the keys to solving a problem from the causes that have the greatest impact on the overall problem. The priority of the problem can be determined after knowing the cause of the dominant problem so that the problem can be solved first.

By referring to these priorities, corrective actions can be more targeted and have a significant impact in resolving other priority issues. Previous research has used this diagram as a quality tool in manufacturing [7], health [8], food [9]. 


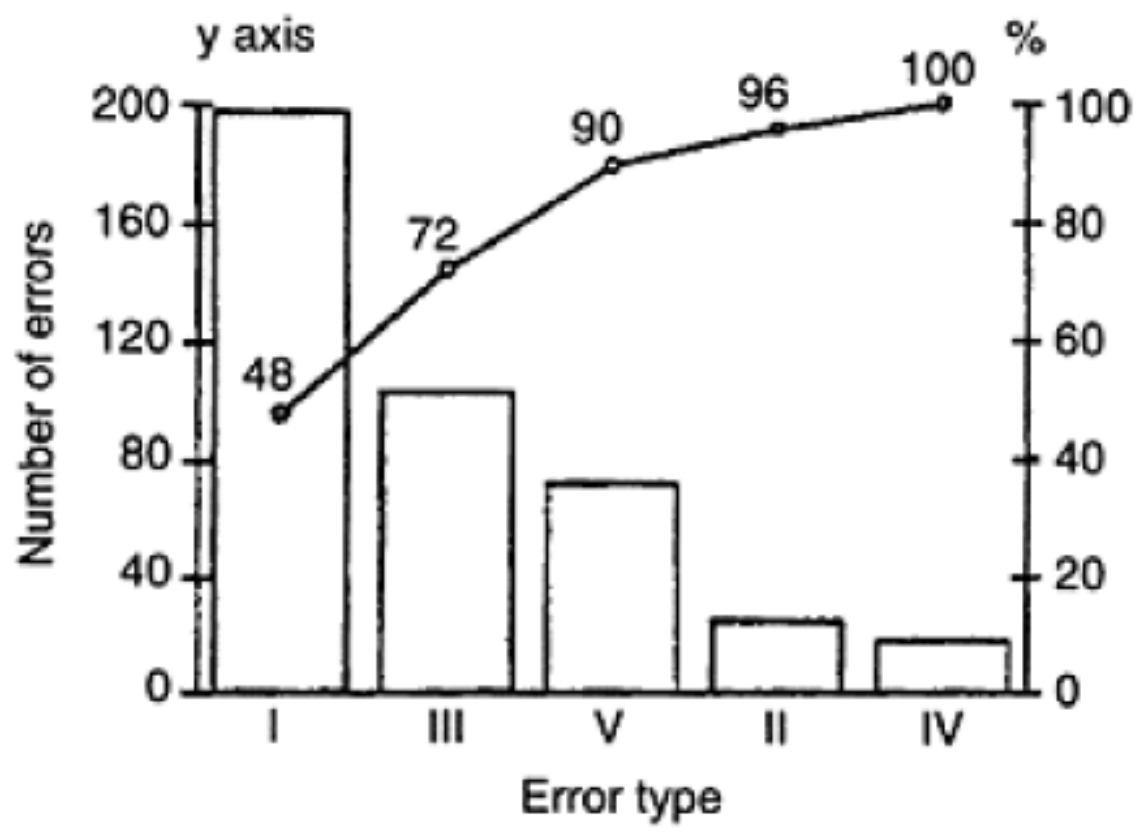

Fig. 2. Pareto Diagram Example

\section{Bayesian Network}

Bayesian network is part of a graphical probability model which consists of qualitative and quantitative parts. the qualitative part is directed acyclic graph where the graph has no iterations in it and consists of nodes and edges. where nodes contain random variables, while edges are between nodes representing dependence between these random variables. Quantitative parts are shaped like marginal priori and probability conditionals to quantify the dependence between connected nodes. This probability calculation has been used in various studies in various fields including manufacturing [10], machinery [1], supply chain [3].

The formula for the Bayesian Network is as follows:

$$
\mathrm{P}(\mathrm{A} \mid \mathrm{B})=(\mathrm{P}(\mathrm{B} \dashv \mid \mathrm{A}) \mathrm{P}(\mathrm{A})) /\left(\mathrm{P}(\mathrm{B} \dashv \mid \mathrm{A}) \mathrm{P}(\mathrm{A})+\mathrm{P}\left(\mathrm{B}+\mathrm{A}^{\wedge} \text { ' }\right) \mathrm{P}\left(\mathrm{A}^{\wedge} \text { ) }\right)\right)
$$

$\mathrm{A}=$ Incidence of delay due to design errors

$\mathrm{A}^{\prime}=$ Event Delay due to change in request 
$\mathrm{B}=$ Event Delay due to error requirements.

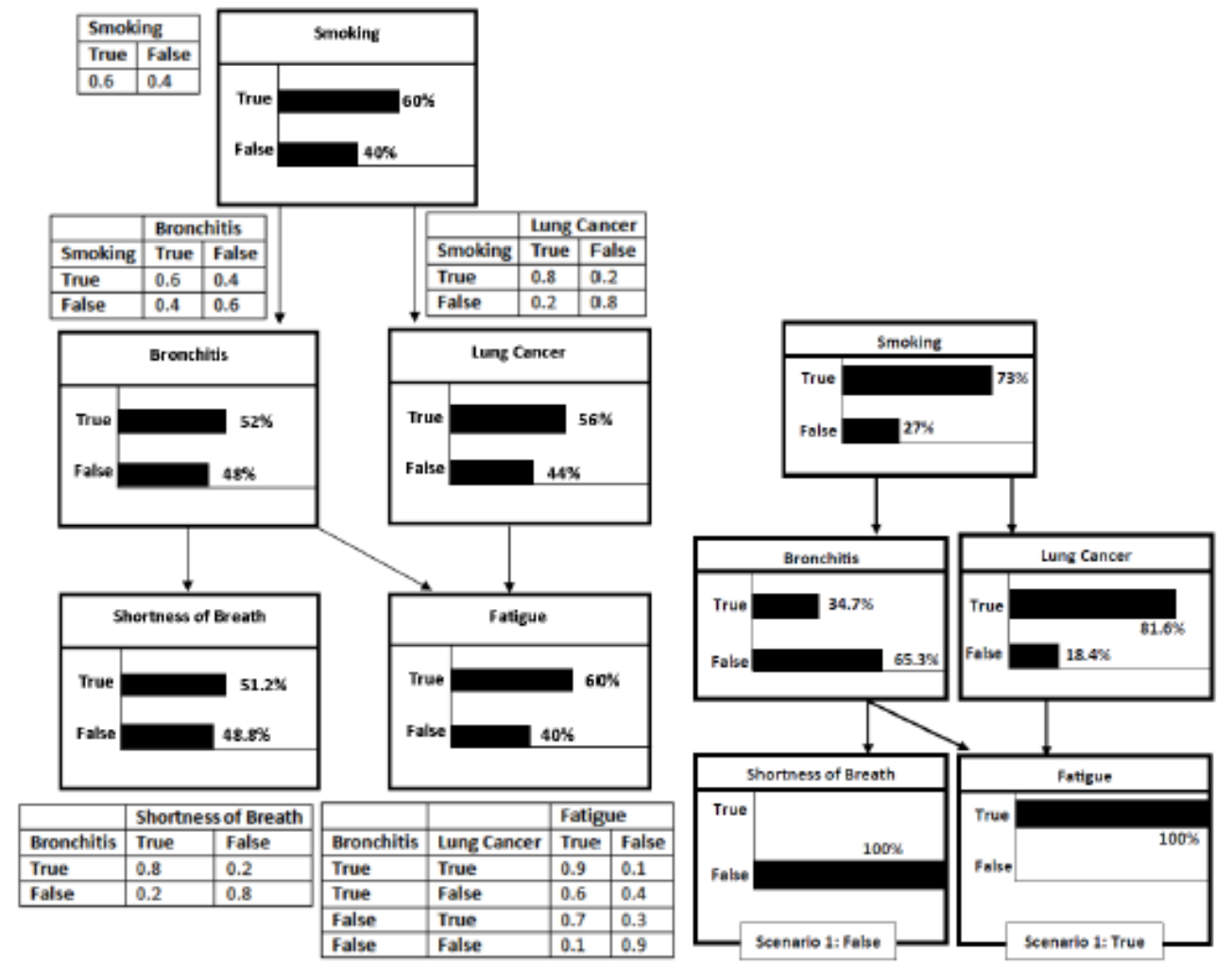

Fig. 3. Bayesian Network Example.

\section{Research Design}

In this research we are using mixed method that using qualitative and quantitative research method. The qualitative research was conducted using a fishbone diagram and a Pareto diagram. While the quantitative research stage is carried out by utilizing the Bayesian network. 


\section{Research method}

Research using a combination of Ishikawa Diagram, Pareto Diagram and Bayesian Theory to find solutions to problems and solutions in industry has been carried out by several researchers, including Kennet (2008), Chockalingam et al. (2019), Rodgers et al. (2019), Chaerani (2010), Fluker et al. (2010), Varzakas (2011).

The form of research data was qualitative and quantitative. Qualitative data were obtained through interviews with internal sources to determine the management of the dominant factors that cause unscheduled SDLCs in the company under research. Whereas Quantitative data are obtained using the frequency of the project under research.

The research scheme is illustrated in Figures $\mathbf{4}$ below. 


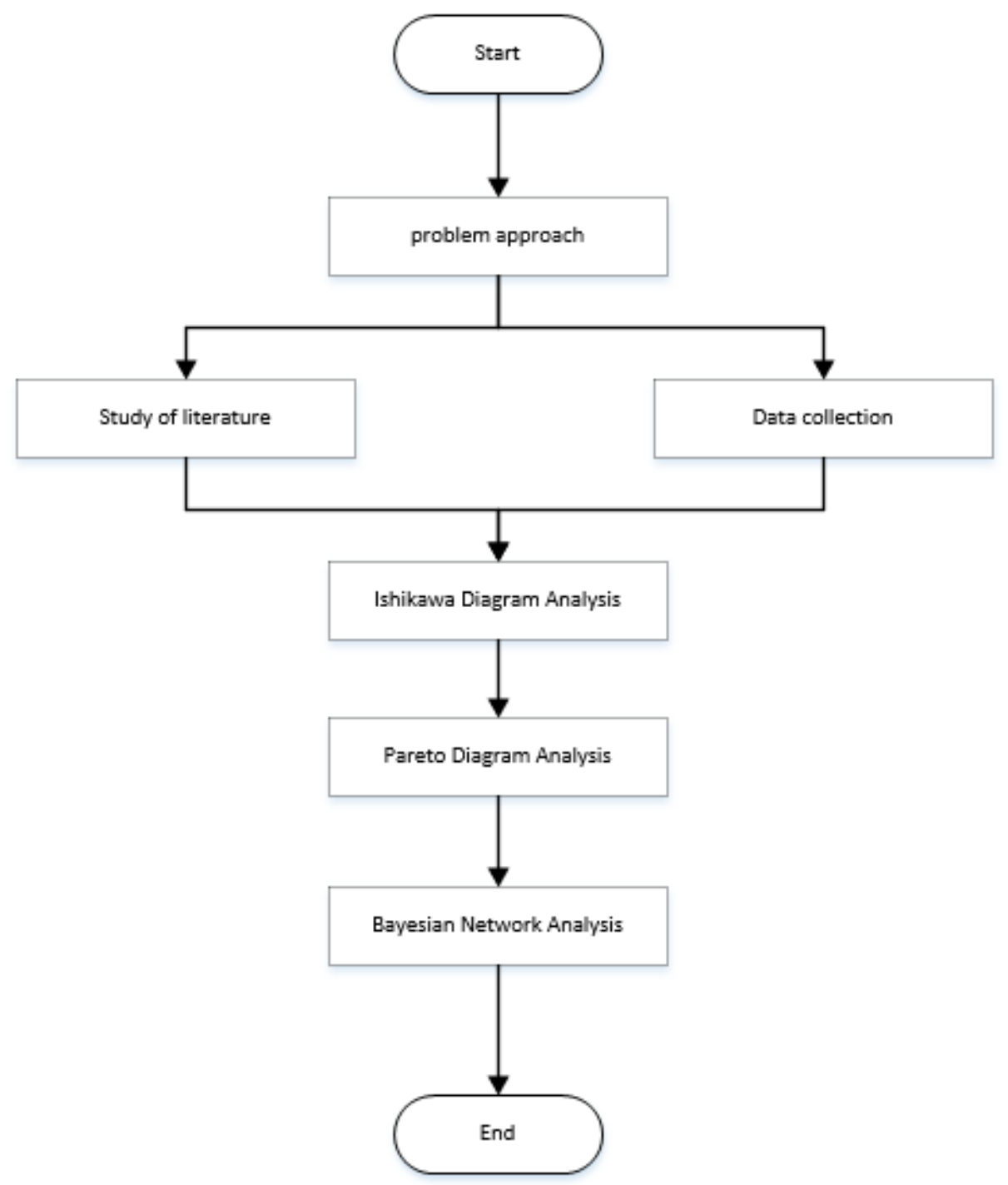

Fig. 4. Research Method.

From Figures 4, we could gain the root cause from every phase from Ishikawa diagram analysis, the frequency of the root causes of each phase from pareto diagram analysis and the probability that these causes arise from bayesian network analysis. 


\section{Result and Analysis}

Based on the analysis result we gain many factors in every phase that causing inacuracy IT project schedule from Ishikawa diagram analysis that desribed in Figures 5.

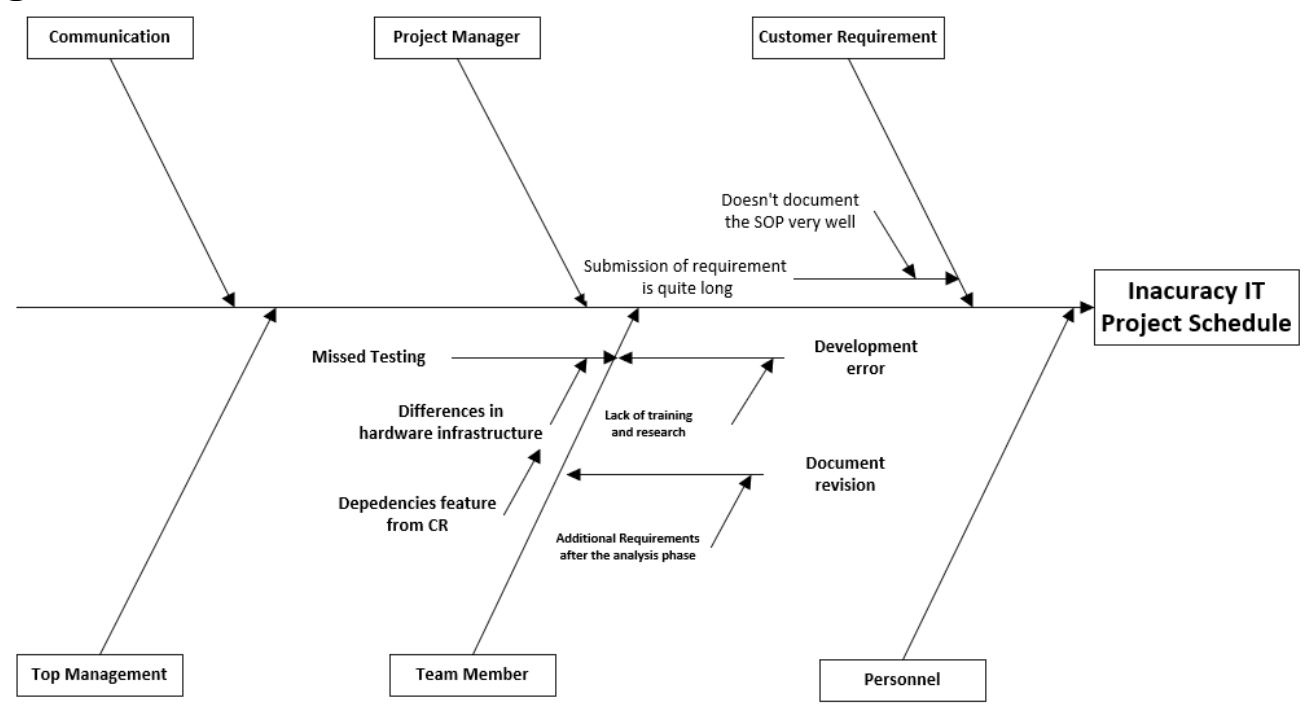

Fig. 5. Ishikawa Diagram Analysis

From the root cause from every phase we calculate the frequency that causing inacuracy IT project schedule that described in Figures 6. From the frequencies of inaccuracies in each phase, it was found that $60.89 \%$ were caused by additional requirements. 


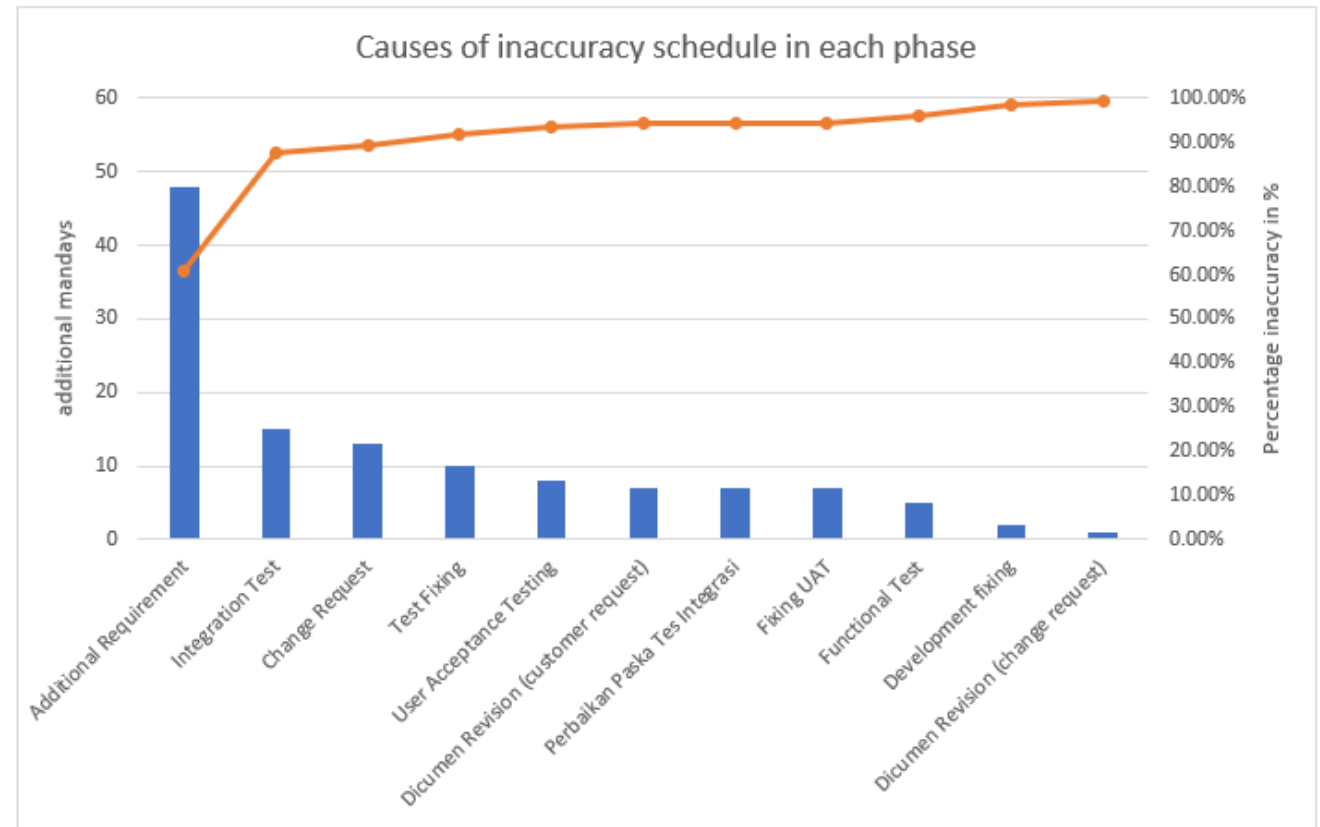

Fig. 6. The overall causes of delay diagram

From the frequency that causing the inaccuracy from every phase, we calculate the probabilites that wll arise that described in Figures 7 that show customer requirements have a big impact on project schedule inacuracy. 


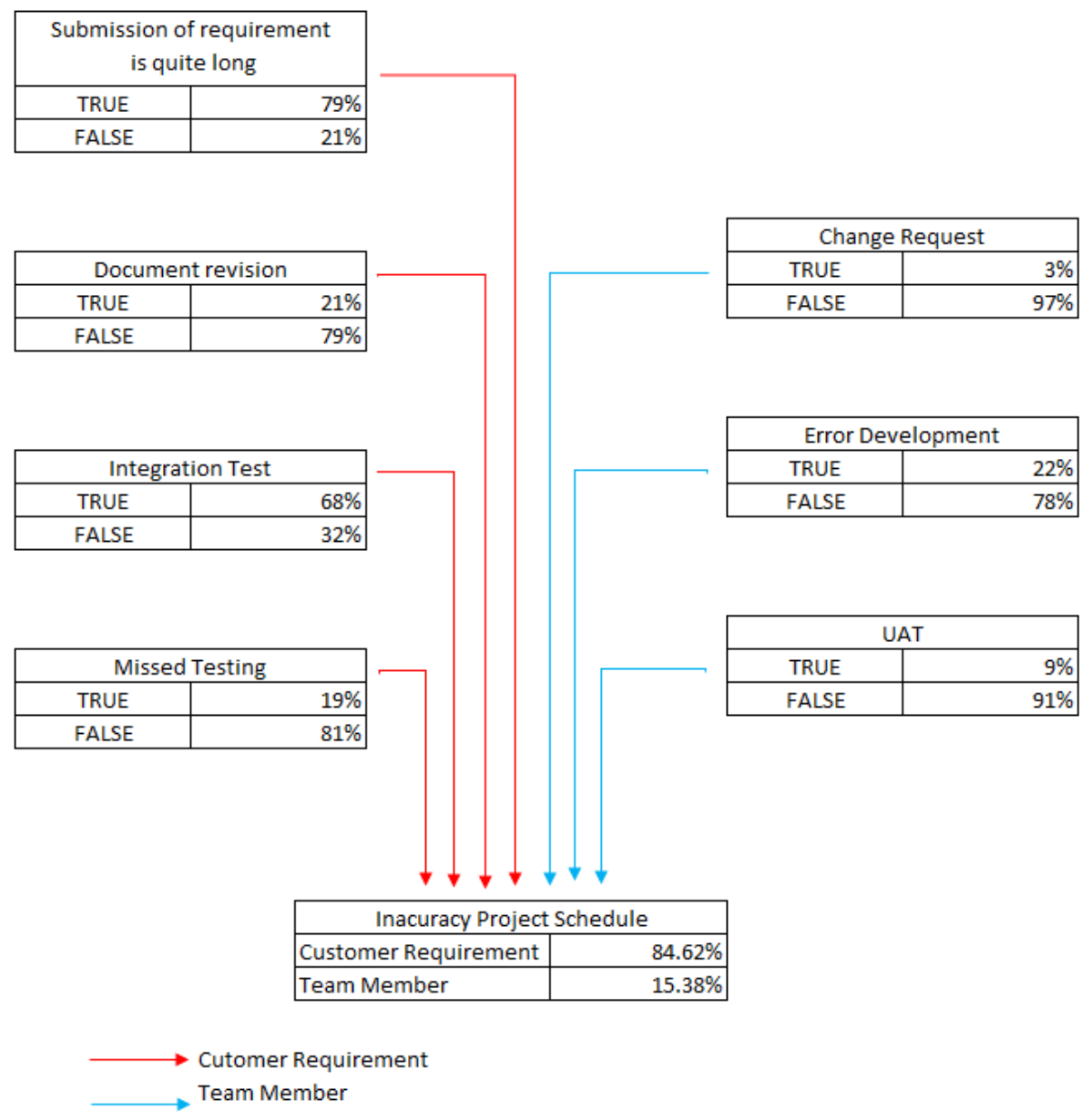

Fig. 7. Bayesian Network

\section{Discussion and Conclusion}

Changes made by customers are based on differences in perceptions of the features desired by customers on the design made. This is discovered during the build and test stage during the integration test. There are additional requirements 
from the integration test results that are still in accordance with the project scope, but are not defined in detail. The company takes the full risk of it in order to get a portfolio of projects as the company has only been standing for two years. The causes of inaccurate project schedules come from Customer requirements and Team Members. Consisting of, Submission of requirements which is quite long, Document Revision, Integration Test, Development Error, Missed Test, and User Acceptance Test

From the results of the Ishikawa diagram analysis, the mapping of the causes in each phase becomes more focused. Based on this analysis, the mapping of the frequency of the causes of inaccurate project schedules comes from the submission of the requirements which are quite long. This is due to the additional requirements outside the phase with a total of $60.98 \%$ of the total additional days of the 23 projects that were not on schedule. From this frequency, 23 projects whose schedule is not correct explain that this cause has a big impact.

Based on the mapping and the frequency, the use of the Bayesian network is needed to determine the probability of causing the project schedule inaccuracy. It was found that $84.62 \%$ were caused by Customer requirements and $15.38 \%$ were caused by Team Members. $79 \%$ of the customer requirements are caused by the submission of the requirements which are quite long due to additional requirements outside the phase.

Based on the mapping results and the probability of the main cause of the inaccuracy of the project schedule, the submission of requirements was quite long due to additional requirements outside the phase. This cause needs to be tackled early so as not to cause problems in the next phase which results in an incorrect project schedule. The impact if this cause is too late to be overcome will cause additional work outside the predetermined schedule so that it requires costs that are beyond the estimate. In addition, potential claims on the quality of project delivery accuracy will be a quality issue in front of customers.

Finally we hope this research could provide more structured insights and knowledge about the inaccuracy IT project schedule or even to another project management. 


\section{References}

1. Chockalingam S, Pieters W, Teixeira A, Khakzad N, Van Gelder P, editors. Combining Bayesian Networks and Fishbone Diagrams to Distinguish between Intentional Attacks and Accidental Technical Failures. International Workshop on Graphical Models for Security; 2018: Springer.

2. Kenett RS. Cause-and-Effect Diagrams. Encyclopedia of statistics in quality and reliability. 2008;1.

3. Rodgers M, Oppenheim R. Ishikawa diagrams and Bayesian belief networks for continuous improvement applications. The TQM Journal. 2019.

4. Schwalbe K. Information technology project management: Cengage Learning; 2015.

5. Njoka KN. Application Of Project Management Tools In Banking Information Systems Development In Kenya: University Of Nairobi; 2012.

6. Myers MD, Avison D. Qualitative research in information systems: a reader: Sage; 2002.

7. Chairani L. Usulan perbaikan kualitas piston 5D9 pada proses machining dengan value engineering untuk mengurangi cacat. 2010.

8. Fluker S-A, Whalen U, Schneider J, Cantey P, Bussey-Jones J, Brady D, et al. Incorporating performance improvement methods into a needs assessment: experience with a nutrition and exercise curriculum. Journal of general internal medicine. 2010;25(4):627-33.

9. Varzakas TH, Arvanitoyannis IS. Application of Failure Mode and Effect Analysis (FMEA), cause and effect analysis, and Pareto diagram in conjunction with HACCP to a corn curl manufacturing plant. Critical reviews in food science and nutrition. 2007;47(4):363-87.

10. Yuniarto HA, Akbari AD, Masruroh NA. Perbaikan Pada Fishbone Diagram Sebagai Root Cause Analysis Tool. Jurnal Teknik Industri. 2013;3(3). 